\title{
A Comparative Analysis of the Frequency and Function of If-clauses in Applied Linguistics and Chemistry Articles
}

\author{
Akbar Hesabi \\ English Department, University of Isfahan, Isfahan, Iran \\ Morteza Raei Dehaghi \\ Department of Industrial Management, Mobarakeh Branch Islamic Azad University, Mobarakeh, Isfahan, Iran \\ Mohammadtaghi Shahnazari-Dorcheh \\ English Department, University of Isfahan, Isfahan, Iran
}

\begin{abstract}
This study investigated the differences and similarities between form and function of if-clauses as one type of conditional clauses within the applied linguistics and chemistry published academic Articles. These articles were examined and after determining the frequency of if-clauses, they were analyzed based on the model proposed by Sweetser (1990). According to the findings, if-clauses were more frequent in applied linguistics than chemistry articles. Results of function analysis indicated that, content is the major function in both applied and chemistry articles and comparing two genres, it is more frequent in applied linguistics articles. Next function in the line is epistemic, and it is again more frequent in applied linguistics articles and speech act was the last function that was more frequent in applied linguistics articles too. In addition, the verb forms of if-clauses were analyzed. Findings indicated that present + present pattern was the most predominant pattern across these two disciplines and it was more frequent in applied linguistics articles, therefore, there can be a relationship between verb pattern and function.
\end{abstract}

Index Terms - conditional clauses, function, content, epistemic, speech act, genre analysis

\section{INTRODUCTION}

Having command of the structure and function of conditional constructions is essential in second language acquisition/learning to enable L2 learners to express themselves accurately and fluently. As a result, conditional constructions are important in English language study, especially for EFL and ESL students.

As mentioned by Warchal (2010) academic communication receives its rhetorical profile by two forces: consensus and disagreement.These two antagonistic needs involve different values. Consensus emphasizes shared knowledge, commonality, as well as shared concepts and attitudes, modesty and respect for the established norms, politeness, but disagreement refers toauthority, individuality, and expertise of the author. Interlocutors can use conditional constructions to express their consensus or disagreement.

There has been an extensive interest in conditional structures that indicates the importance of this construction. Many philosophers, linguists and grammarians proposed numerous typologies, like Comrie (1986) on semantic distinctions; Sweetser (1990) on the conceptual domains, and Kitis (2002) on verb morphology and tense sequencing. He discussed the rhetorical function of some conditional structures that can have a concessive or even antithetical (contrastive) force. Ferguson (2001) in his research about conditional in medical discourse focuses on a variety of semantic, pragmatic, and formal aspects of conditionals, and Dancygier \& Sweetser (2005) analyzed the function of if -clauses. Later CarterThomas \& Rowley-Jolivet (2008) analyzed the function of if- Conditional in medical discourse. In 2008 Max M. Louwerse, Scott A. Crossley and Patrick Jeuniaux investigated the linguistic features of conditionals that have extensively been studied in philosophy, psychology and education. Warchal (2010) investigated the function of conditional clause in linguistic research articles.

Function of if-clause based on Sweetser's model has been the interest of some researchers as: Lily I-wen Su (2005) who investigated the Chinese conditional as used in conversation, her findings showed that, content conditional was more than epistemic and speech act ones, with about $\% 60$,epistemic conditional about $\% 29$ and speech act conditional about \% 11 . The paper has shown the important roles played by context and the pragmatic concerns necessary in the interpretation of Chinese conditionals as they are used in spontaneous spoken discourse.

Warchal (2010) investigated the function of conditional clause in linguistic research articles. He analyzed 200 electronically research articles from linguistic journals for the frequency and function of if-clauses according to Sweeter's model (1990). The author reported that the most frequent functional category among if-clauses found in the corpus of linguistic research articles under study is content conditionals, accounting for 57\% of all data. The next 
predominate function was epistemic conditionals, with $23 \%$ of the occurrences. By using epistemic conditionals, the writer is able to share the responsibility for the claim made in the main clause with the receiver.

According to Warchal (2010, p.147)

"The knowledge of the truth of the proposition in the protasis leads to the acceptance of the proposition in the apodosis. Once the reader concedes that the former is true, s/he is likely to arrive at the same conclusion, presented in the main clause, as the author. In this way rather than authoritatively supplied, the claim can be formulated by both parties seemingly independently."

The examined data in Warchal's research shows that, If-clauses function predominantly as content conditionals. As Warchal (2010) puts it

"this prototypical type of if-conditionals expresses the subject-matter relation of condition in discourse and aims at showing the way in which one state of affairs is contingent on another. Its predominant function is therefore ideational. In addition, a high percentage of conditional clauses express presentational relations in discourse and aim at creating conditions in which the reader can favourably receive the author's claim. It is in these cases that the interpersonal potential of if-clauses comes to the fore as part of the dialogue established between the author and the audience in search for shared understanding and consensus."

This paper focuses on one type of these linguistic tools (if-clauses) employed by scholars in their academic texts to reach consensus, express disagreement or communicate their ideas, in other words it studies if-clauses as a rhetorical device for gaining acceptance for one's claims. It will present an analysis of functions and forms if clauses play in research articles in an attempt to identify the differences between two fields of study in applying these devices for writing scientific articles. For this purpose, Sweetser's (1990) theoretical framework of dividing if-clauses based on their function to content, epistemic and speech act was used.

\section{THEORETICAL FOUNDATION}

\section{A. Content Conditionals}

Warchal (2010, p.143) gives the following definition for content conditional

"The conditional clause typically conveys a condition which, if fulfilled, ensures the truth of the proposition in the main clause. The central issue in such direct conditions is then the relationship between the main and the subordinate clause, as the former expresses a situation that is contingent on that expressed by the latter.... Content conditionals are the only group of conditional clauses where the ideational function clearly prevails, although in the case of hypotheticals the interpersonal meaning seems to co-occur with the content function."

In the content conditional, a causal relation exist between the consequent of a conditional and the events and situations in the content domain. Dancygier and Sweetser (2005) stated that, content conditional is a predictive conditional. They referred to mental spaces theory, according to which, there exist three kind of spaces, content, epistemic and speech act space.

As an example, they mentioned:

If I tie my handkerchief around it, it'll stick.

They stated, "We might say that this speaker is first engaged in setting up a space of mental content, this is a space which is about a possible state of affairs in his world, namely the situation where he ties his handkerchief around the cut. Within this space, the speaker predicts an added aspect of the content of this mental space: The handkerchief will stick to the cut.

They predict this result only in the space set up by the if-clause: there is no prediction about the handkerchief sticking to the cut if it is not being used to bandage it. These contingency relations are part of the structure of the represented content: that is, the speaker is talking about a possible attempt at bandaging, and the conditional construction marks his representation of a contingent relationship between that portrayed event and its predicated result". (Dancygier \& Sweetser, 2005).

\section{B. Epistemic Conditionals}

Sweetser (1990) states that in epistemic conditionals:

"knowledge of the truth of the hypothetical premise expressed in the protasis would be a sufficient condition for concluding the truth of the proposition expressed in the apodosis" (p. 116).

Warchal (2010, p.144) believes that "their function may resemble that of emphatics, since they present the proposition in the main clause as a logical and necessary consequence of the already negotiated or unquestioned premise."

As Sweetser (1990) mentioned in the epistemic domain, an inferential relation exists between what is assumed in the antecedent of a conditional and what is concluded in its consequent. Moreover, according to Dancygier and Sweetser (2005), speakers set up an epistemic space, unlike causality in the world and reasoning processes may operate either from known cause to likely effect, or from known effect to possible cause. Sweetser (1990) and Dancygier \& Sweetser (2005) provided the following examples for this type of conditionals:

- If the lights are on then he will be at home. (Sweetser, 1990)

- If he typed her thesis, he loves her. (Dancygier \& Sweetser, 2005) 
According to above examples the reasoning (If he typed her thesis) is performed, and the conclusion (he loves her) is drawn, and in the other example, there is a reasoning (If the lights are on) and then conclusion (he will be at home).

\section{Speech act Conditionals}

Sweetser (1990, p. 118) writes about speech act conditionals as follows:

"the performance of the speech act represented in the apodosis is conditional on the fulfillment of the state described in the protasis (the state in the protasis enables or causes the following speech act)."

In addition, she provides this example "If you wouldn't mind, please sit here".

Dancyiger and Sweetser (2005) state that in speech act conditional, there is an "appropriacy" relation between the antecedent and consequent. They clarify this point by giving an example:

- If I do not see you before Thursday, have a good Thanks giving! (Dancygier \& Sweetser, 2005)

The speaker does not predict something about a good Thanksgiving on the basis of information about seeing the addressee before Thursday. Rather, the speaker sets up a discourse context, a speech-act space wherein Thursday has arrived without her seeing the hearer, and then utters a speech act which is to be taken as effective within that space. Any contingency relationship marked by if must be interpreted as holding not between the contents of the two clauses, but rather between the possible scenario portrayed in the if-clause and the speaker's act of well wishing. (Dancygier \& Sweetser, 2005).

This division between three types of if-clauses by Sweetser (1990) constitutes the theoretical foundation of this study.

\section{OBJeCTIVES OF THE STUDY}

The first aim of this study is, to examine the frequency of if-clauses in applied linguistics and chemistry articles. A second aim is to investigate the functions of if-clauses in these two disciplines, based on Sweetser's (1990) model. A valid description of if-clause patterns in applied linguistics and chemistry articles allow us to make comparison across disciplines. A third aim is to address the question of whether there are any differences between applied linguistics articles and chemistry articles in terms of the frequency and function of if-clauses used in them.

\section{RESEARCH QUESTIONS}

For the above-mentioned aims the following questions were developed:

1. What is the frequency of if-clauses used in published articles of applied linguistics and chemistry?

2. What are the most predominant functions to which if-clauses are put in these two disciplinary areas?

3. To what extent is there evidence to support similarity and/or differences between the two disciplines in terms of frequency and function of if clauses?

\section{CORPUS}

Firstly, in terms of the selection of the discipline, the present study collected texts from the disciplines of applied linguistics as a representative of soft sciences and chemistry articles as a representative of hard sciences. Applied linguistics is of particular interest to EFL community for pedagogic reasons and chemistry is a common course that is thought in universities. The data for this study comprise fifty research articles from two disciplines, twenty-nine articles belonging to chemistry, and twenty-one articles belonging to applied Linguistics. Applied linguistics articles are all taken from leading international and EFL journals during 2007-2010, and chemistry articles are taken from journals in science direct database during 2007-2010 too. This study focused on only the body part of each article. The total number of words in the body parts of applied linguistics and chemistry articles was almost the same.

\section{DATA}

\section{A. Frequency of Occurrences of the If Clauses}

For finding frequency of if-clauses in applied linguistics and chemistry articles, all articles were analyzed twice (all footnotes, endnotes, and reference lists were deleted). Then the frequency of occurrence of if-clauses in each discipline was determined and recorded. Table 1 presents the frequency of occurrences of the if-clauses across applied linguistics and chemistry articles.

TABLE 1.

FREQUENCY AND PERCENTAGE OF IF-CLAUSES IN APPLIED LINGUISTICS AND CHEMISTRY ARTICLES

\begin{tabular}{|l|l|l|l|}
\hline & Applied linguistics articles & Chemistry articles & total \\
\hline Frequency & 70 & 52 & 122 \\
\hline$\%$ & $\% 57.4$ & $\% 42.6$ & $\% 100$ \\
\hline
\end{tabular}

B. Functions of If-clauses in Applied Linguistics Articles

The functional categories used in this study are based on Sweetser's (1990) division of if-clauses into content, epistemic and speech-act conditionals, which act as the framework for the present analysis. For this purpose two 
examiners distinguished the type of if clauses. The inter rater reliability based on Pearson correlation was 0.71 . Table 2 shows if-clauses function and their frequency across these two disciplines.

TABLE 2

FUNCTIONS OF IF-CLAUSES AND THEIR FREQUENCY ACROSS TWO DISCIPLINES

\begin{tabular}{|l|l|l|l|l|l|l|}
\hline Applied linguistics & frequency & $\%$ & Chemistry & \multicolumn{2}{l|}{ Total } \\
\hline function & 36 & $\% 29.5$ & f & $\%$ & \\
\hline Content & 25 & $\% 20.5$ & 32 & $\% 26.1$ & 68 \\
\hline Epistemic & 9 & $\% 7.4$ & 17 & $\% 14$ & 42 \\
\hline Speech act & 70 & $\% 57.4$ & 3 & $\% 2.5$ & 12 & $\% 35.6$ \\
\hline Total & 52 & $\% 42.6$ & 122 & $\% 100$ \\
\hline
\end{tabular}

\section{Verb form Patterns in Conditionals: Variation across Genres}

Table 3 provides an overview of the frequency distribution of the most common verb forms in protasis and apodosis across the two disciplines.

TABLE 3.

VERB FORMS IN CONDITIONAL SENTENCES: VARIATION ACROSS TWO DISCIPLINES

\begin{tabular}{|l|l|l|l|}
\hline Verb forms in protasis +apodosis & applied linguistics & chemistry & Total(n=122) \\
\hline Present+present & $31(\% 25.3)$ & $26(\% 21.3)$ & $57(\% 46.6)$ \\
\hline Present+modal (e.g might, can ) & $14(\% 11.4)$ & $13(\% 10.5)$ & $26(\% 21.9)$ \\
\hline Present+will & $9(\% 7.4)$ & $7(\% 5.6)$ & $16(\% 13.1)$ \\
\hline Past+would & $9(\% 7.4)$ & $4(\% 3.2)$ & $13(\% 10.5)$ \\
\hline Past perfect+would & $1(\% 0.7)$ & - & $1(\% 0.7)$ \\
\hline Past+past & $5(\% 4)$ & - & $5(\% 4)$ \\
\hline Past+modal (e.g. might, can) & $4(\% 3.2)$ & - & $4(\% 3.2)$ \\
\hline Sub total & 70 & 52 & 122 \\
\hline
\end{tabular}

Note. The percentages were calculated based on the total number of if-conditionals in two disciplines.

In terms of the first question, as the findings show and presented in table 1, if-clauses are more frequent in applied linguistics articles than in chemistry articles. According to this table, in applied linguistics $70(\% 57.4)$ and in chemistry 52 (\%42.6) occurrences of if-clauses were found.

Concerning the second question, table 2 indicates that if there should be a hierarchy, most of the if-clauses belong to content domain, then enter the epistemic domain, and end in speech act domain. According to the finding presented in table 2, content if-clauses should be taken as the major type we identified among if-clauses found in these two corpora, with \%29.5 in applied and \% 26.1 in chemistry articles. The next predominant function in both corpora is epistemic, with \%20.5 and \% 14 in applied linguistics and chemistry articles respectively. As the results show speech act if clauses are the less frequent ones in chemistry and applied linguistics articles.

According to table 3 the majority of patterns is present + present in both corpora. They are more frequent in applied linguistics articles with \%25.3 and \%21.3 in chemistry articles. Present + modal is the next pattern with about \%11.4 and $\% 10.5$ in applied and chemistry articles respectively. This pattern is again more frequent in applied articles. Present + will pattern is more frequent (\%7.4) in applied linguistics articles than chemistry articles (\%5.6) too. Also past + would pattern is more frequent in applied (\%7.4) than chemistry (\%3.2) articles. Other patterns like Past perfect + would, Past + past and Past + modal (e.g. might, may, can) were not found in chemistry articles but they were rare in applied linguistics articles with $\% 0.7, \% 4$, and $\% 3.2$ respectively.

\section{DATA ANALYSIS}

The results of this study indicated that if-clause constructions were more frequent in applied linguistics than chemistry articles and analyzing their functions shows that content if-clauses are the predominate function in two corpora, and then epistemic and at the end speech act ones. Regarding the frequency of content if-clauses, they are more frequent in applied linguistics articles than chemistry articles.

Examining the verb form of if-clauses, the present + present pattern was the predominant pattern across these two disciplines and it can be concluded that most content conditional should have present + present pattern.

The other purpose of this thesis was to compare the function of if-clauses in applied with those in chemistry, representative of hard science and soft science. Findings indicated that there was a difference between these two disciplines. Content, epistemic and speech act if-clauses were more frequent in applied than chemistry articles. Also finding of verb forms indicated that present+ present, present + modal, present + will and Past + would patterns are the predominate forms in applied linguistics and chemistry articles but this patterns are more frequent in applied linguistics articles. Past perfect + would, past + past and past + modal are the forms that cannot be found in chemistry articles.

This finding somehow is in line with Warchal (2010), investigated the function of conditional clause in linguistic research articles. He analyzed 200 electronically research articles from linguistic journals for the frequency and function of if-clauses according to Sweetser (1990). The author reported that content conditionals are the most frequent 
functional category among if-clauses found in the corpus of linguistics research articles under study, accounting for $57 \%$ of all occurrences.

Also Carter-Thomas and Rowley-Jolivet (2008) in their analysis of three genres of medical discourse: research articles, conference presentations, and editorials, showed that the preferred function was factual conditionals $(68 \%$ of occurrences). He mentioned, that the need to 'facticity' establishment in medical research and to detail the precise conditions under which the research was conducted are the effective factors. As Warchal (2010, p.146) puts it:

"This prototypical function of if-clauses also reflects the major preoccupation of academic texts, which is that of establishing the relationship between states that have the status of facts, drawing conclusions from these relationships and promoting these conclusions to the status of facts."

According to Sweetser (1990) content conditional, which can be named predictive conditional, if fulfilled, ensures the truth of the proposition in the main clause.

The next predominant function in both corpora is epistemic, \%35.5 and \%32.5 in applied linguistic and chemistry respectively. In findings of the other researchers like Warcha1 (2010), epistemic is the second predominant function of if-clauses, about $\% 23$ of the data. It seems that the writer employs epistemic conditionals to share the responsibility for the claim made in the main clause with the receiver.

Speech act conditional is the remaining percentage of the if-clause's function, about \%13 and \%6 in applied linguistic and chemistry articles respectively. An indirect condition can be expressed by Speech act conditional and it is not related to the situation expressed in the main clause. In addition, the knowledge that the proposition in the if-clause is true is not sufficient to conclude that the other proposition is true as well. "In these cases," writes Sweetser (1990, p. 118), "the performance of the speech act represented in the apodosis is conditional on the fulfillment of the state described in the protasis (the state in the protasis enables or causes the following speech act)."

\section{CONCLUSION AND IMPLICATIONS}

In terms of pedagogical implications, instead of focusing on the verb-form paradigm in EFL setting, this study can introduce and help instructors consider other categorizations of the if-clauses based on the findings in other points of view. Second, as genre analysis is an important part of ESP courses and if-clauses vary across genres, preparing pedagogic activities and material with an orientation toward the differences between genres and how if-clauses are imployed can be useful for the students.

Accordingly, analyzing the functions of if-clauses in this study provides an explicit model, however incomplete, of these genres. Since this study compare applied linguistic and chemistry articles, it can also help language teachers and learners to develop a conscious recognition of the difference between function of if-clauses across these two disciplines. Besides, it provides information about the tense patterns of if-clauses in these two genres, and as a result, the difference of these two text types not only in the type of if-clauses but also in tense patterns becomes explicit. Therefore, the findings try to provide the model expressed before for these two genres explicitly and help the text writers to apply it for writing effectively.

The finding of the present study can also clarifies the dimensions in which applied linguistic and chemistry articles differ. Therefore, it can contribute to a kind of conscious awareness of the function of if-clauses that can assist the students in writing articles that are more comprehensible. Besides having enough knowledge of type and tense pattern of if-clauses help students to use more effective and precise sentences in their writing different texts and avoid using inappropriate type and tense patterns in expressing their opinions.

\section{SUGGESTION FOR FURTHER RESEARCH}

In this study, the frequency and function of if-clauses in chemistry and applied linguistic articles were analyzed. It would also be interesting to look into the function of conditional clauses in various academic disciplines. This study analyzed the functions of conditionals in written academic discourse, spoken form can be consider too. It would also be interesting, and necessary, to contrast data from applied and chemistry with other disciplines. The order of clauses, protasis and apodosis- in conditional sentences, in different disciplines can be analyzed too.

\section{REFERENCES}

[1] Carter-Thomas, Shirley, Rowley-Jolivet, Elizabeth. (2008). If-conditionals in medical Discourse; from theory to disciplinary practice. Journal of English for Academic Purpose. 7. 191-205.

[2] Comrie, Bernard. (1986). Conditionals: a typology. On Conditionals, In. Closs Traugott, A. ter Meulen, J. Snitzer Reilly and C. A. Ferguson (Eds.), 77-99. Cambridge. Cambridge University Press.

[3] Dancygier, Barbara, Sweetser, Eve. (2005). Mental spaces in grammar. Cambridge. Cambridge University Press.

[4] Ferguson, Gibson. (2001). If you pop over there: a corpus-based study of conditionals in medical discourse. English for Specific Purposes. 20.61-82

[5] I-wen Su, Lily. (2005). Conditional reasoning as a reflection of mind. Language and linguistics. 6(4): 655-680.

[6] Kitis, Ellis. (2002). "On the Modern Greek conditional connective an, or towards restoring the image of the Greek culture". M. Makri Tsilipakou (ed.) Selected Papers on Theoretical and Applied Linguistics. From the $14^{\text {th }}$ International Symposium. April 20-22, 2000, Aristotle University, Thessaloniki: University Studi Press, 154-174. 
[7] Louwerse, Max, Crossley, Scott, Jeuniaux, Patrick. (2008). What if? Conditionals in educational registers. Linguistics and Education. 19(1). 56-69.

[8] Sweetser, Eve. (1990). From etymology to pragmatics: Metaphorical and cultural aspects of semantic structure. Cambridge: Cambridge University Press.

[9] Warcha1, Krystyna. (2010). Moulding interpersonal relations through conditional clauses: Consensus-building strategies in written academic discourse. Journal of English for Academic Purposes, 9, 140-150.

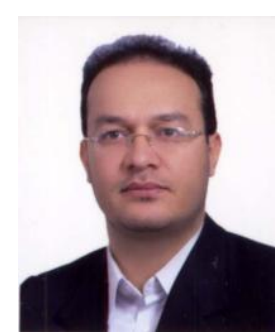

Akbar Hesabi PhD in linguistics is currently Assistance Professor at English Department, University of Isfahan, Iran. His areas of interest include Linguistics, Neurolinguistics, and Computational Linguistics. He has published several articles in these areas.

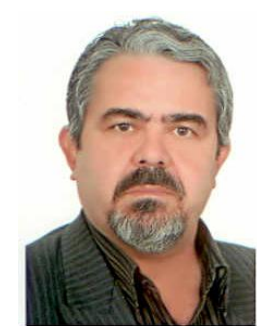

Morteza Raei Dehaghi was born in Dehagh, a province of Najafabad, Isfahan, Iran on May 1, 1955. He finished Bachelor of Science in Electrical Engineering at Mapua Institute of Technology, Manila, Philippines, 1980, Master of Business Administration, major in Industrial Management and Doctor of Business Administration, at Manuel L. Quezon University, Manila, Philippines, 1991 and 1993 respectively.

He worked in Modhej Thermal Power Plant as an Operational Engineer; Ministry of Foreign Affairs as a Consular and Students Affairs Officer; Councilor in Dehagh province as a President and Islamic Azad University - Mobarakeh Branch as an Assistant Professor at Mobarakeh, Isfahan. He wrote the book, Specialized English for the Students of Industrial Management; Isfahan, Iran: Jahad Daneshgahi, 2001, and wrote the articles, Nuclear Energy and Its Environmental Worries; International Conference on Power Plants; Vrnjacka Banja, Serbia, Oct. 26-29, 2010 and Cost Comparison between Nuclear and Fossil Fuel Power Plants ICEESD 2011; Bangkok, Thailand, 2011.

$\mathrm{He}$ is a member of Iran Management Association (IMA); Isfahan Association of Professional Engineers and Management Scientific Association of Mobarakeh Azad University.

Mohammadtaghi Shahnazari-Dorcheh has a Ph.D in Language Teaching and Learning from the University of Auckland. Dr. Shahnazari is currently an Assistant Professor in the Department of English Language and Literature, University of Isfahan. His research interests are interactional corrective feedback, individual differences in working memory capacity, reading comprehension and SLA issues. He has presented and published several papers in international conferences and journals. 